\title{
Comparative Study of Droplet Transfer Modes on Appearance, Microstructure, and Mechanical Properties of Weld during Pulsed GMAW
}

\author{
Peizhuo Zhai ${ }^{1}$, Songbai Xue ${ }^{1, * \mathbb{D}}$, Jianhao Wang ${ }^{1}{ }^{\mathbb{D}}$, Yu Tao ${ }^{1}$, Weizhong Chen ${ }^{2}$, Tao Chen ${ }^{1}$ and \\ Shilei Ji ${ }^{2}$ \\ 1 College of Materials Science and Technology, Nanjing University of Aeronautics and Astronautics, \\ Nanjing 210016, China; zhaipz@nuaa.edu.cn (P.Z.); wangjh@nuaa.edu.cn (J.W.); \\ taoyu1995@nuaa.edu.cn (Y.T.); taocmsc@nuaa.edu.cn (T.C.) \\ 2 Kunshan Huaheng Welding Co., Ltd., Kunshan 215347, China; wz.chen@huahengweld.com (W.C.); \\ sl.ji@huahengweld.com (S.J.) \\ * Correspondence: xuesb@nuaa.edu.cn; Tel.: +86-025-8489-6070
}

Received: 16 April 2020; Accepted: 6 May 2020; Published: 8 May 2020

\begin{abstract}
Droplet transfer plays a crucial role in welding stability and quality of pulsed gas metal arc weld (GMAW), referring to the process of heat and mass transition. In this work, the appearance, microstructure, microhardness, tensile properties, and impact toughness with three typical modes of droplet transfer in pulsed GMAW (ODMP: one drop per multiple pulses; ODPP: one drop per pulse; MDPP: multiple drops per pulse) were studied and compared. The results showed that the better welding appearance, the deeper penetration, and the less fume covered on the steel plate could be found during the ODPP welding process. At the same wire feeding speed and arc length, the average current was similar in ODPP and MDPP conditions. However, the average current in the ODMP condition was about 15 A larger than the other two, contributing to the higher heat input. Compared with MDPP and ODMP, the longest elongation and impact energy of the welded joint were found in the ODPP condition. Furthermore, the decrease of elongation and impact toughness in the ODMP condition might result from the higher heat input and the coarsen microstructure, like the proeutectoid ferrite and ferrite side plate.
\end{abstract}

Keywords: pulsed GMAW; droplet transfer; welding appearance; microstructure; mechanical properties

\section{Introduction}

In the past decades, the increasingly fierce competition of the commercial industry has put much emphasis on efficiency, which gives impetus to the development of manufacturing automation. Gas metal arc weld (GMAW), a method in which liquid metal droplets are formed and detached from the electrode wire, is widely used in automatic manufacturing and robot welding because of high productivity and reliable usability [1,2].

However, the traditional GMAW is performed by a constant voltage direct-current (DC) welding power source. Because of the electric explosion of the liquid bridge before the arcing period, the spatters are inevitably produced in short-circuiting transfer under the condition of short arc and low current [3]. This drawback can be overcome by pulsed GMAW technology due to the special pulse waveform and droplet transfer mode [4-8]. Besides, pulsed GMAW also has the advantages of controllable heat input and all position welding [9-11].

Droplet transfer plays an important role in welding stability and quality, referring to the process of heat and mass transition [12-17]. There are three typical modes of droplet transfer in the pulsed 
GMAW process, namely, "one drop per multiple pulses" (ODMP), "one drop per pulse" (ODPP), and "multiple drops per pulse" (MDPP). ODPP has been recognized as the most ideal transfer mode for many references, with the focus mostly on the waveform of ODPP and the study of welding stability [18-22]. However, the effects of droplet transfer modes on the final goal of welding, obtaining high-quality weld joints, have been rarely researched and are not clear for now.

Therefore, the influences of droplet transfer modes on welding appearance, microstructure, and mechanical properties were studied and compared in this work. The research results are useful to optimize the welding parameters, choose the appropriate droplet transfer mode, and gain the high-quality weld joints in pulsed GMAW. Furthermore, the application of pulsed GMAW can also be promoted further in industrial automation production and robot welding.

\section{Experimental Procedures and Equipment}

\subsection{Welding and High-Speed Camera System}

Droplets fly through the arc at high speed during the pulsed GMAW process [23]. In order to distinguish the modes of droplet transfer, high-speed cameras are wildly applied to observe the droplets [24,25]. Figure 1 displays the schematic diagram of the welding and high-speed camera system in this work. As shown in Figure 1, the high-speed camera at 10,000 fps was fixed on the ground. For the continuous capture of arc images, the arc should be relatively static with the camera. Thus, the welding torch (including the contact tube) was fixed over the workpiece, which could be moved by the motion platform at a constant speed. In addition, the high brightness light was radiated from the arc, resulting in hard observation of the droplets in an arc. Therefore, a narrow-band filter $(850 \mathrm{~nm})$ was set between the arc and the high-speed camera to weaken the arc light, while a laser light $(850 \mathrm{~nm})$ was used as a backlight to enhance background and contrast of images. Moreover, the data acquisition card could acquire synchronous voltage and a current signal corresponding to images.

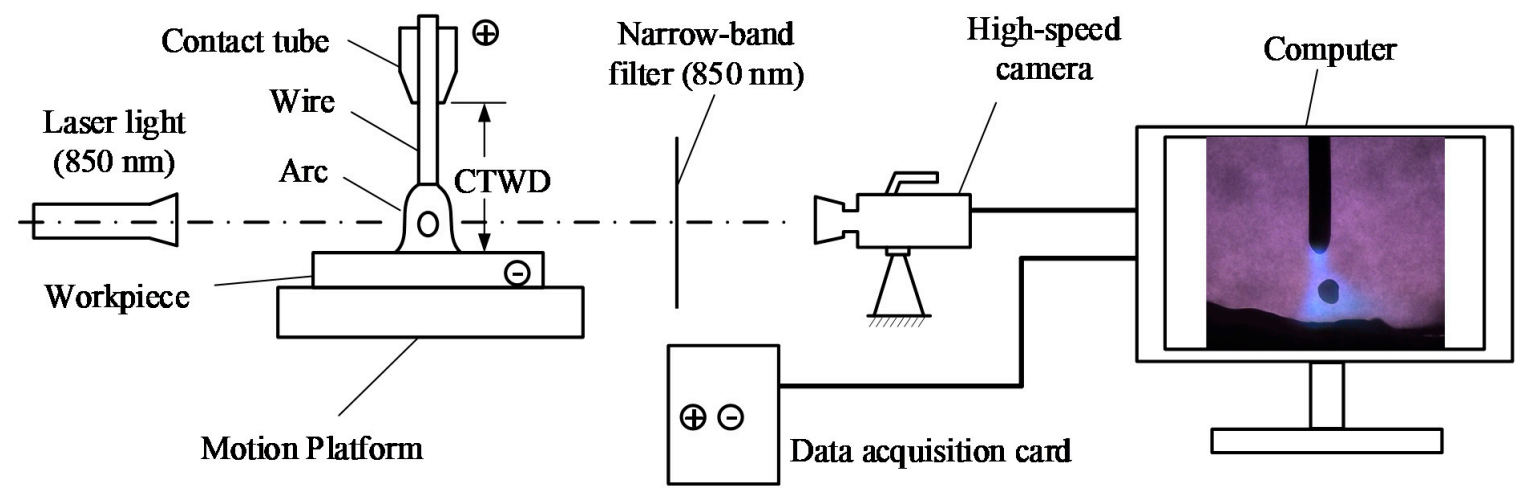

Figure 1. The schematic diagram of the welding and high-speed camera system.

\subsection{Materials and Welding Parameters}

Q345 is typical low alloy steel, which is commonly used in construction engineering, vehicles, ships, pressure vessels, and so on. It is easy to be obtained at low cost and does not need preheating before welding. In this paper, our theme was studying droplet transfer modes on appearance, microstructure, and mechanical properties of the weld during pulsed GMAW. So, the extra influence of preheating could be avoided by choosing this representative material, highlighting the focus of this comparative study. Therefore, the base materials were Q345 steel plates with two kinds of a thickness $(6 \mathrm{~mm}$ and $12 \mathrm{~mm}$ ), and the welding wire used was $1.2 \mathrm{~mm}$ diameter ER50-6 (copper coated). The chemical composition and mechanical properties of the base metal and welding wire are listed in Tables 1 and 2, respectively. The CTWD (contact tube-to-work distance) was set as $20 \mathrm{~mm}$. The mixture of $\mathrm{Ar}+18 \%$ $\mathrm{CO}_{2}$ gas was used as the shielding gas, and the flow rate was $18 \mathrm{~L} / \mathrm{min}$. A welding speed of $4 \mathrm{~mm} / \mathrm{s}$ 
and a wire feeding speed of $4 \mathrm{~m} / \mathrm{min}$ were chosen. The plates were cleaned and polished to remove the grease dust and oxide layer before welding.

Table 1. The chemical composition of the base metal and welding wire.

\begin{tabular}{cccccccc}
\hline \multirow{2}{*}{ Materials } & \multicolumn{7}{c}{ Chemical Composition (wt.\%) } \\
\cline { 2 - 8 } & C & Mn & Si & S & P & Cu & Fe \\
\hline Q345 & 0.16 & 1.35 & 0.29 & 0.015 & 0.016 & 0.11 & Bal. \\
ER50-6 & 0.09 & 1.57 & 0.91 & 0.015 & 0.013 & 0.23 & Bal. \\
\hline
\end{tabular}

Table 2. The mechanical properties of the base metal and welding wire.

\begin{tabular}{ccccc}
\hline \multirow{2}{*}{ Materials } & \multicolumn{4}{c}{ Mechanical Properties } \\
\cline { 2 - 5 } & $\begin{array}{c}\text { Yield Strength } \\
\mathbf{( M P a )}\end{array}$ & $\begin{array}{c}\text { Tensile Strength } \\
\mathbf{( M P a )}\end{array}$ & $\begin{array}{c}\text { Elongation } \\
\mathbf{( \% )}\end{array}$ & $\begin{array}{c}\text { Impact Energy } \\
\mathbf{( J )}\end{array}$ \\
\hline Q345 & $\geq 345$ & $470-630$ & $\geq 29$ & $\geq 34\left(20^{\circ} \mathrm{C}\right)$ \\
ER50-6 & $\geq 400$ & $\geq 490$ & $\geq 22$ & $\geq 27\left(-30^{\circ} \mathrm{C}\right)$ \\
\hline
\end{tabular}

Considering the standard Charpy V-notch impact specimens were $50 \mathrm{~mm} \times 10 \mathrm{~mm} \times 10 \mathrm{~mm}$, the thickness of the sample was required to be more than $10 \mathrm{~mm}$. Therefore, the metallurgical and mechanical characterization were all made on welded samples (60 V-groove) with $12 \mathrm{~mm}$ thickness. However, the arc and droplets in the V-groove of $12 \mathrm{~mm}$ thickness samples were hardly observed during the welding process. Thus, for the convenience of the capture of images of the droplets, the judgment of droplet transfer mode, and comparing the appearance of the single weld bead, a bead-on-plate weld was performed on the $6 \mathrm{~mm}$ plates first. By adjusting the pulse current waveform, three typical modes of droplet transfer (ODMP, ODPP, and MDPP) were obtained at the same length of the arc (4 mm). The heat input $Q(\mathrm{~J} / \mathrm{mm})$ could be calculated as follows according to the European Standard EN 1011-1:

$$
Q=k \times \frac{U \times I}{v}
$$

where $k$ is the efficiency of GMAW, $U$ is the average voltage, $I$ is the average current, and $v$ is the welding speed. The effective power of GMAW is in the range of $0.7-0.8$. In this work, $k$ was considered to be 0.8 . The parameters of waveforms and experiments are displayed in Table 3 , and the waveforms and high-speed photographs are shown in Figure 2.

Table 3. The parameters of waveforms and experiments.

\begin{tabular}{cccccc}
\hline Test & $\begin{array}{c}\text { Droplet Transfer } \\
\text { Modes }\end{array}$ & $\begin{array}{c}\text { Pulse Frequency } \\
f / \mathbf{H z}\end{array}$ & $\begin{array}{c}\text { Average Current } \\
\boldsymbol{I}_{\mathbf{a}} / \mathbf{A}\end{array}$ & $\begin{array}{c}\text { Average Voltage } \\
\boldsymbol{U}_{\mathrm{a}} / \mathbf{V}\end{array}$ & $\begin{array}{c}\text { Heat Input } \\
\boldsymbol{Q} /(\mathbf{J} / \mathbf{m m})\end{array}$ \\
\hline 1 & $\mathrm{ODMP}^{1}$ & 129 & 128 & 24.4 & 625 \\
2 & $\mathrm{ODPP}^{2}$ & 96 & 113 & 23.8 & 538 \\
3 & $\mathrm{MDPP}^{3}$ & 68 & 115 & 23.1 & 531 \\
\hline
\end{tabular}

With the purpose of stable ODPP transfer, pulse current waveform, shown in Figure 2b, was selected according to the reference [20]. The pulse peak current $\left(I_{p}\right)$ and pulse peak current time $\left(t_{p}\right)$ are generally regarded as the main parameters that affect pulsed droplet transfer mode. Moreover, the power-law relationship $\left(I_{p}^{n} T_{p}=\right.$ constant) is applied in lots of studies to determine the peak current and time [21,22]. On the basis of the ODPP waveform, the $I_{\mathrm{p}}$ and $t_{\mathrm{p}}$ were adjusted smaller, as shown in Figure 2a. The smaller arc force to promote the droplet detachment was obtained, resulting in the ODMP transfer mode. In contrast, $t_{\mathrm{p}}$ was longer than that in ODPP, contributing to enough energy and arc force in a single pulse to form the MDPP transfer mode, as shown in Figure 2c. According to 
the statistical analysis, the average metal transfer frequency of ODMP, ODPP, and MDPP was 62, 96, and $136 \mathrm{~Hz}$, respectively.
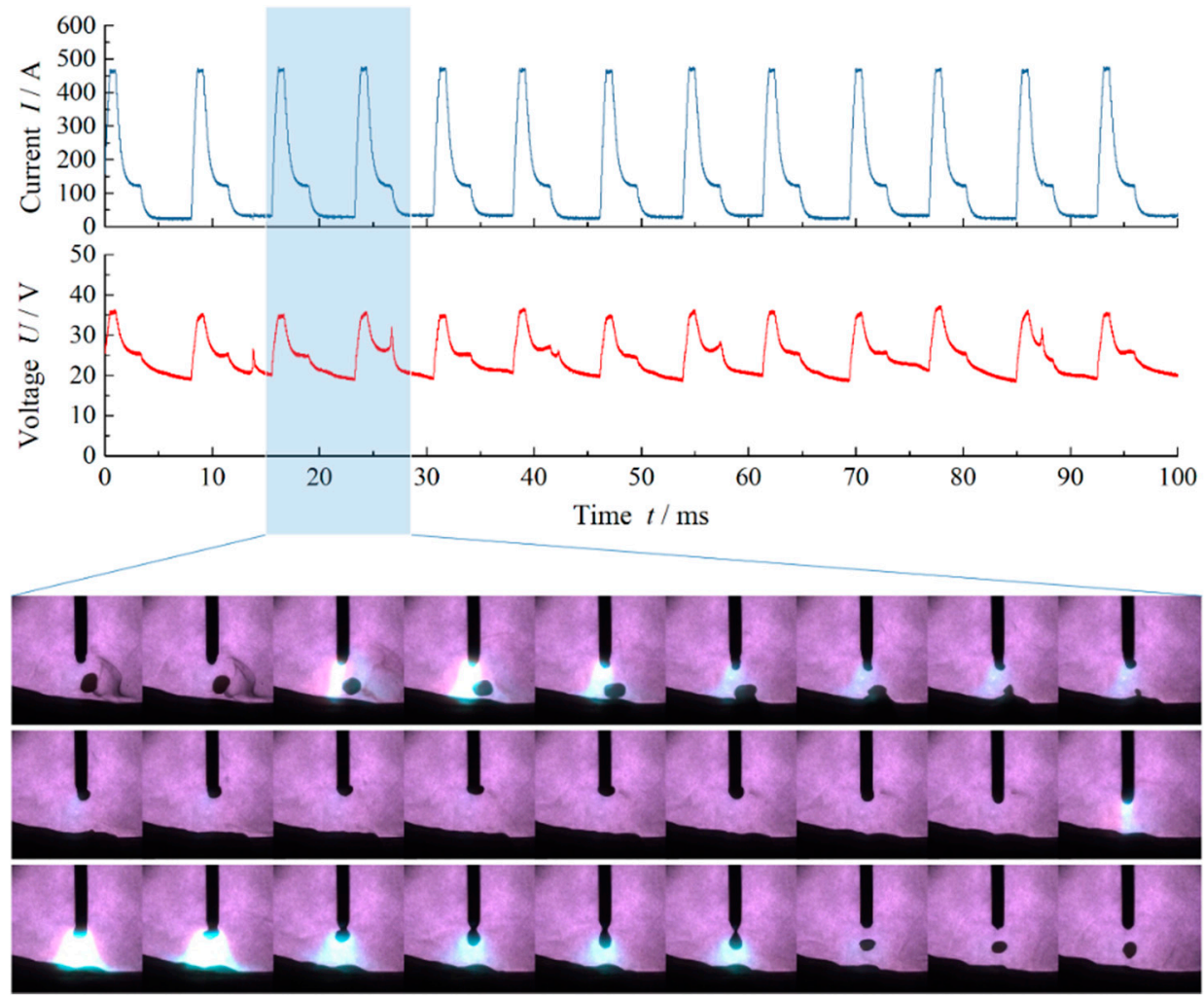

(a)
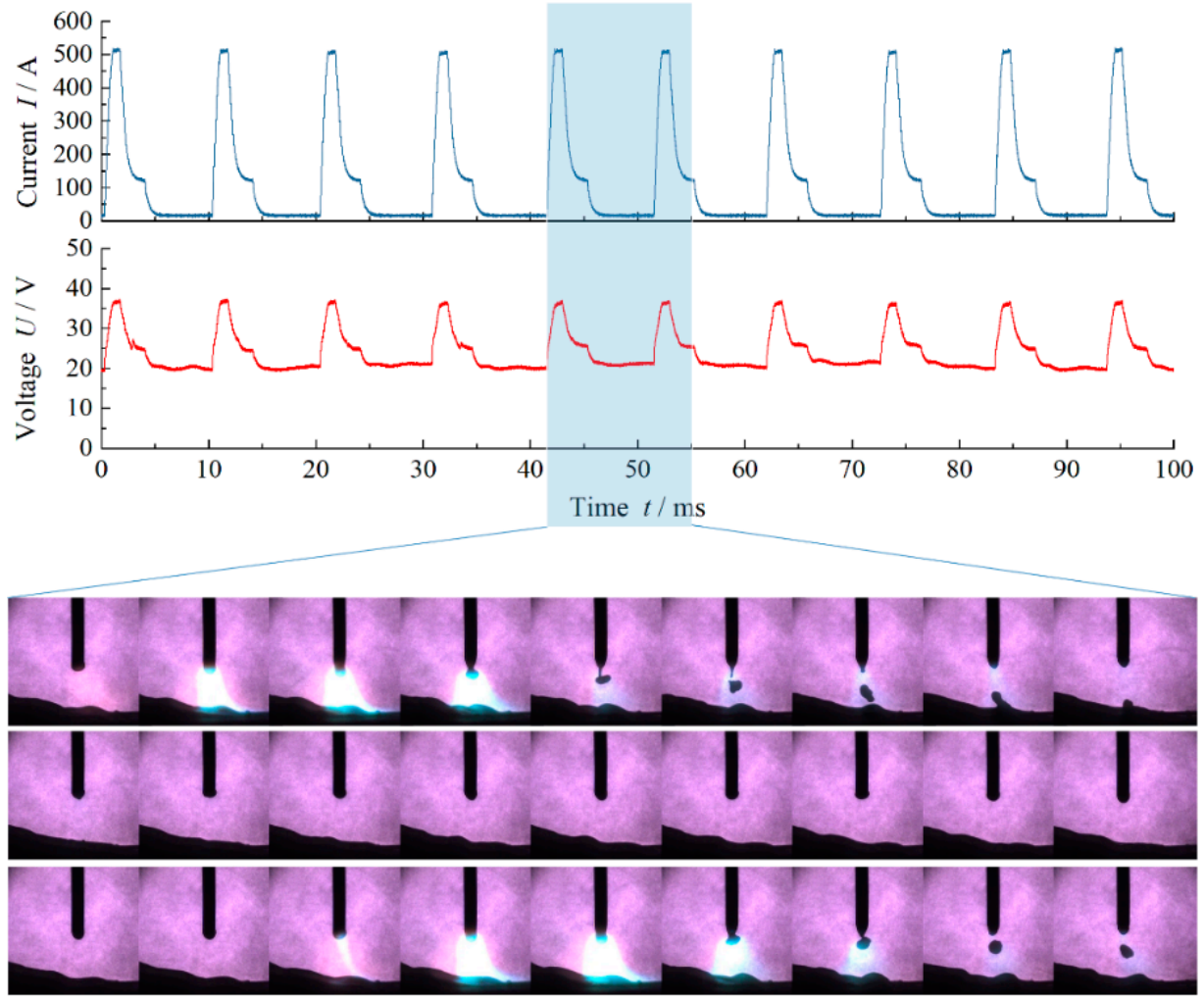

(b)

Figure 2. Cont. 

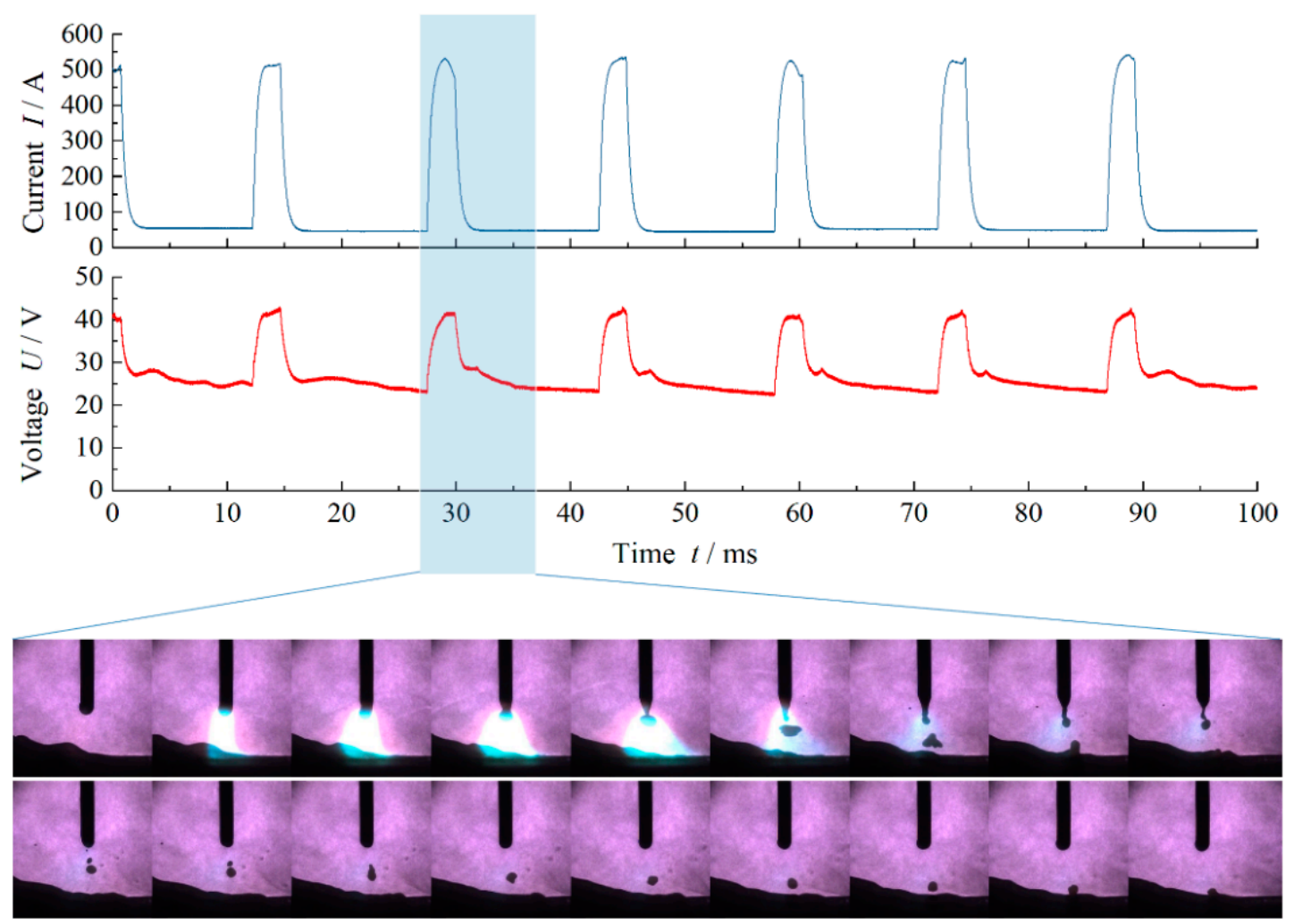

(c)

Figure 2. The waveforms and high-speed photographs of three typical modes of droplet transfer: (a) one drop per multiple pulses (ODMP); (b) one drop per pulse (ODPP); (c) multiple drops per pulse (MDPP).

Then, $12 \mathrm{~mm}$ thick steel couples with butt joints $\left(60^{\circ} \mathrm{V}\right.$-groove) were welded using the ODMP, ODPP, and MDPP waveforms listed in Table 3, respectively. The multi-pass welding was carried out to fill the weld groove at the top ( 5 passes), and a single pass was performed at the bottom after back gouging. Those butt joints were used in the observation of microstructures and mechanical testing.

\subsection{Appearance and Microstructure Characterization}

In order to compare the surface appearance and cross-section appearance of weld beads, photos of bead-on-plate weld beads without cleaning were captured, and the cross-section specimens were cut from the $6 \mathrm{~mm}$ welded plates. Furthermore, the cross-section specimens were cut for the analysis of microstructures from the $12 \mathrm{~mm}$ butt joints. All specimens were ground with different sizes of metallographic abrasive papers first. Then, cloth for polishing with a $3 \mu \mathrm{m}$ diamond paste was used to polish the specimens. After polishing, the specimens were etched by acid chemical reagent $\left(4 \% \mathrm{HNO}_{3}+96 \%\right.$ absolute alcohol). The microstructures were observed by an optical microscope.

\subsection{Mechanical Testing}

The Vickers microhardness profiles of the cross-sectional welded joints were performed on an HVS-1000 microhardness tester (ShangHai Caikon Optical Instrument Co., Ltd, Shanghai, China) following ASTM: E384. The load was chosen as $200 \mathrm{~g}$ with a dwell time of $15 \mathrm{~s}$.

According to AWS: B4 specifications [26], the tensile test specimens were cut from the $12 \mathrm{~mm}$ welded plates in the perpendicular direction to the welding seam. Then, the tensile tests were carried out on a WAW-300B (300 kN, Zhejiang Jingyuan Mechanical Equipment Co., Ltd., Jinhua, China) tensile test machine with a speed of $6 \mathrm{~mm} / \mathrm{min}$. 
The Charpy V-notch impact specimens $(50 \mathrm{~mm} \times 10 \mathrm{~mm} \times 10 \mathrm{~mm})$ were prepared for the impact tests. The notch direction was consistent with the welding direction. The impact tests were carried out on a JB-300B (300 J, Changzhou Sanfeng Instrument Technology Co., Ltd., Changzhou, China) impact test machine with $20^{\circ} \mathrm{C}$. In order to increase the precision, three specimens were tested in each condition during tensile and impact tests.

\section{Results and Discussion}

\subsection{The Appearance of Weld Bead}

The surface appearance and cross-section appearance of weld beads with three typical modes of droplet transfer are displayed in Figures 3 and 4, respectively. Generally speaking, it could be seen from Figure 3 that the surfaces of the three beads were all straight and bright. The edges of beads were also fused well, and there were no spatters or incomplete fusion defects. However, compared with ODMP and ODPP beads, the more obvious ripples were found on the surface of the MDPP bead. In addition, in terms of brown welding fume near the beads on the steel plates, the least fume was found in the ODPP condition. In contrast, the entire steel plate was almost covered by welding fume in Figure 3a. The amount of fume covered on the steel plate in the MDPP condition was between the ODPP and ODMP welding process. The qualitative relationship could be found by the visual method: the amount of fume covered on the steel plate after welding in the ODPP condition was less, which could save time in cleaning the surface of the workpiece and improve production efficiency.

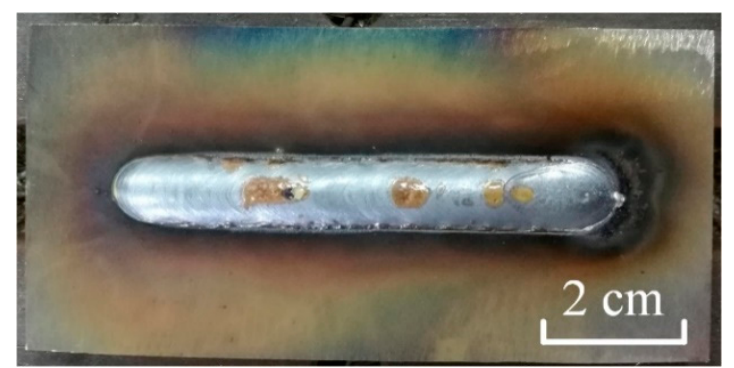

(a)

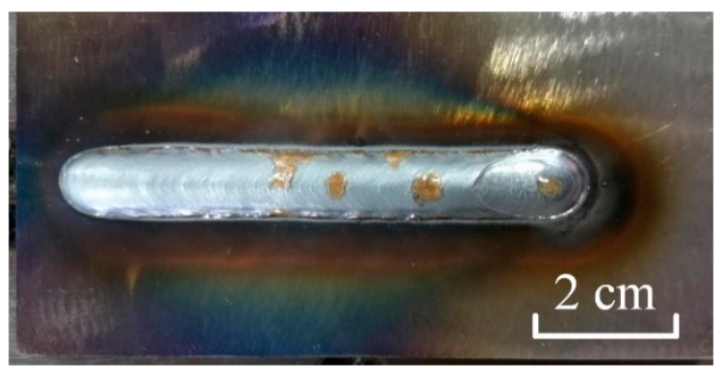

(b)

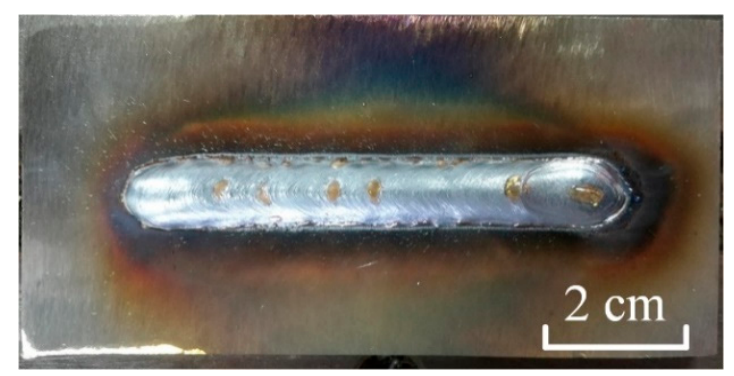

(c)

Figure 3. The surface appearance of beads with three typical modes of droplet transfer: (a) one drop per multiple pulses (ODMP); (b) one drop per pulse (ODPP); (c) multiple drops per pulse (MDPP). 


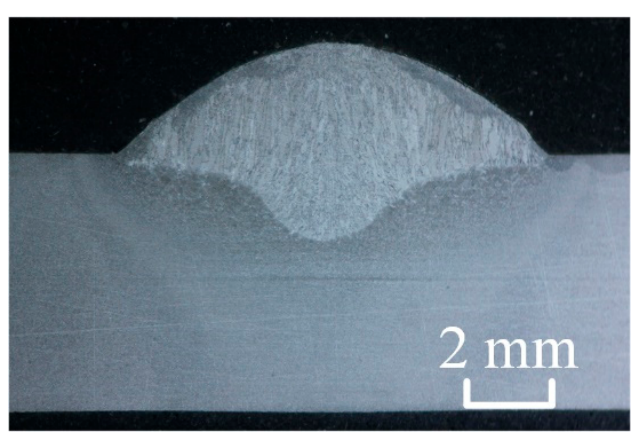

(a)

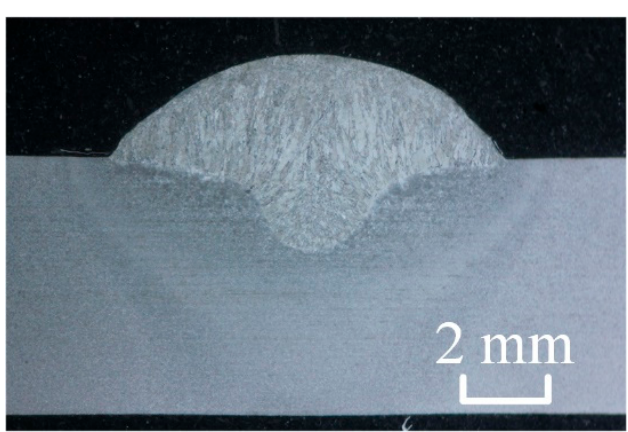

(b)

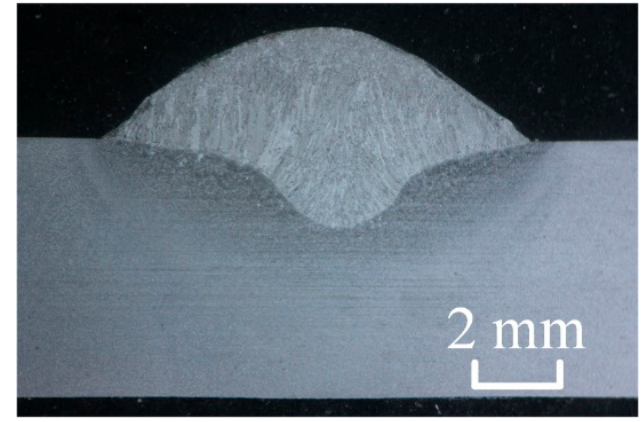

(c)

Figure 4. The cross-section appearance of beads with three typical modes of droplet transfer: (a) one drop per multiple pulses (ODMP); (b) one drop per pulse (ODPP); (c) multiple drops per pulse (MDPP).

The parameters of the cross-section appearance of beads are listed in Table 4. Based on Figure 4 and Table 4, we could see that the cross-section appearance of beads was pretty similar in ODMP and MDPP conditions. A more rounded cross-section surface was obtained in the ODPP condition, whose bead width and bead height were smaller. Moreover, a deeper penetration was gained in the ODPP condition, which was about 10\% deeper than that in ODMP and MDPP conditions. The depth of penetration might be influenced by the main impact frequency of droplet transfer on the molten pool. As mentioned in Section 2.2, the average metal transfer frequency of ODMP, ODPP, and MDPP was 62, 96, and $136 \mathrm{~Hz}$, respectively. However, Figure 2c shows that the second droplet was much smaller and slower than the first in the process of MDPP, which indicated that the main impact on the molten pool resulted from the first bigger and faster droplet. Thus, the main impact frequency on the molten pool of ODMP, ODPP, and MDPP could be regarded as 62,96 , and $68 \mathrm{~Hz}$, respectively. The largest frequency was found in ODPP, which contributed to the deepest penetration compared with ODMP and MDPP.

Table 4. The parameters of the cross-section appearance of beads.

\begin{tabular}{cccc}
\hline Droplet Transfer Modes & Bead Width $(\mathbf{m m})$ & Bead Height $(\mathbf{m m})$ & Penetration $(\mathbf{m m})$ \\
\hline ODMP & 9.98 & 2.59 & 2.03 \\
ODPP & 9.28 & 2.44 & 2.22 \\
MDPP & 9.95 & 2.59 & 2.04 \\
\hline
\end{tabular}

\subsection{Microstructure Analysis of Weld}

Figure 5 shows the optical microstructures of weld metal with three typical modes of droplet transfer. The mixture of proeutectoid ferrite (PF), ferrite side plate (FSP), acicular ferrite (AF), and a small amount of Bainite (B) could be found in the weld metal. The PF distributed along the grain boundary of austenite, and the FSP grew into the grains. From Table 3, the average current in the ODMP condition was about 15 A larger than that in ODPP and MDPP conditions. As could be seen in 
Figure 2, the droplets could detach from the wire tip during one pulse in ODPP and MDPP conditions. In the ODMP condition, the droplet was heated by arc on the tip of the wire during two or three pulses, which could not detach in time. As a result, the droplet was overheated, and higher heat input and current were needed in the ODMP condition compared with ODPP and MDPP. The PF and the FSP were more and coarser in Figure 5a, which might be caused by the higher heat input. The longest PF found in Figure 5a-c was circled, whose length was approximately $350 \mu \mathrm{m}, 130 \mu \mathrm{m}$, and $180 \mu \mathrm{m}$, respectively. However, the distribution of grains was more uniform in Figure $5 \mathrm{~b}$. As mentioned in Section 3.1, the largest frequency of the main impact on the molten pool was found in ODPP. Under the impact of droplets, the stirring effect of the molten pool was enhanced. Therefore, the more uniform distribution of grains in the ODPP condition could be obtained, even though the average current and heat input were similar in ODPP and MDPP conditions [27].

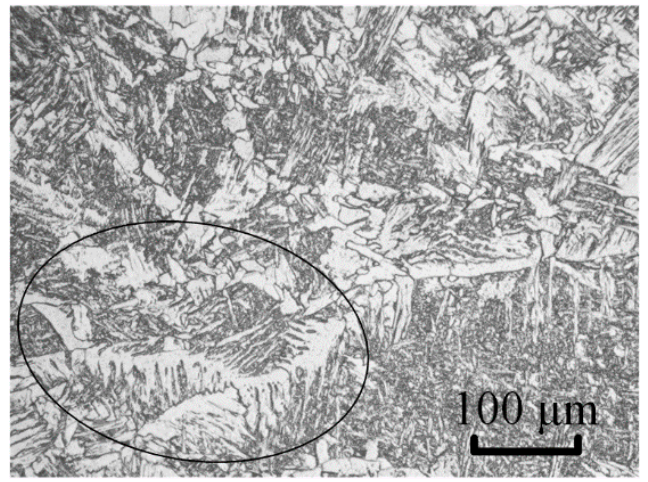

(a)

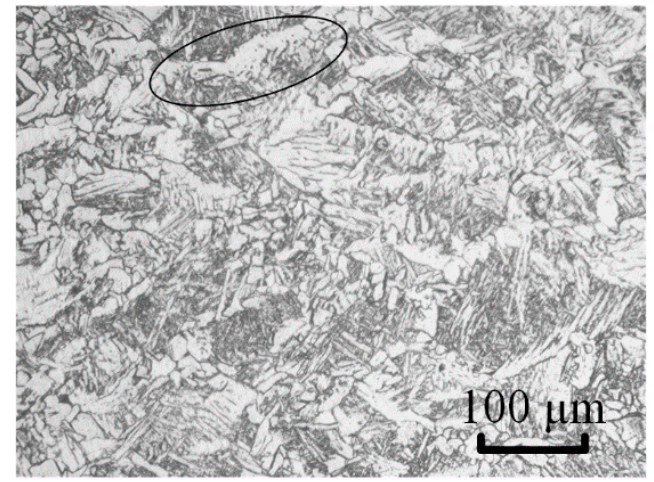

(b)

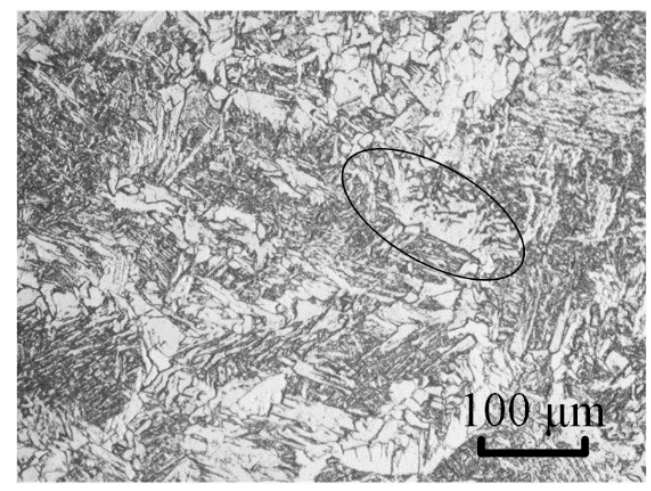

(c)

Figure 5. Optical microstructures of weld metal with three typical modes of droplet transfer: (a) one drop per multiple pulses (ODMP); (b) one drop per pulse (ODPP); (c) multiple drops per pulse (MDPP).

\subsection{Microhardness and Tensile Properties of Welded Joint}

The microhardness curve of welded joints with three typical modes of droplet transfer is displayed in Figure 6. The common feature here was that the distribution of microhardness was uneven, and the maximum microhardness was found in the heat-affected zone (HAZ) in all-welded specimens. This was because the cooling rates of base metal near the weld zone (WZ) was higher, leading to the formation of a high-hardness martensite structure [26,28]. The hardness of base metal (BM) and WZ was similar. The average microhardness of WZ in the ODMP condition was a little lower than that in ODPP and MDPP conditions, which might be due to the coarse PF and FSP structure in higher heat input welding process [29]. Besides, the uneven distribution of grains explained the fluctuation of microhardness. 


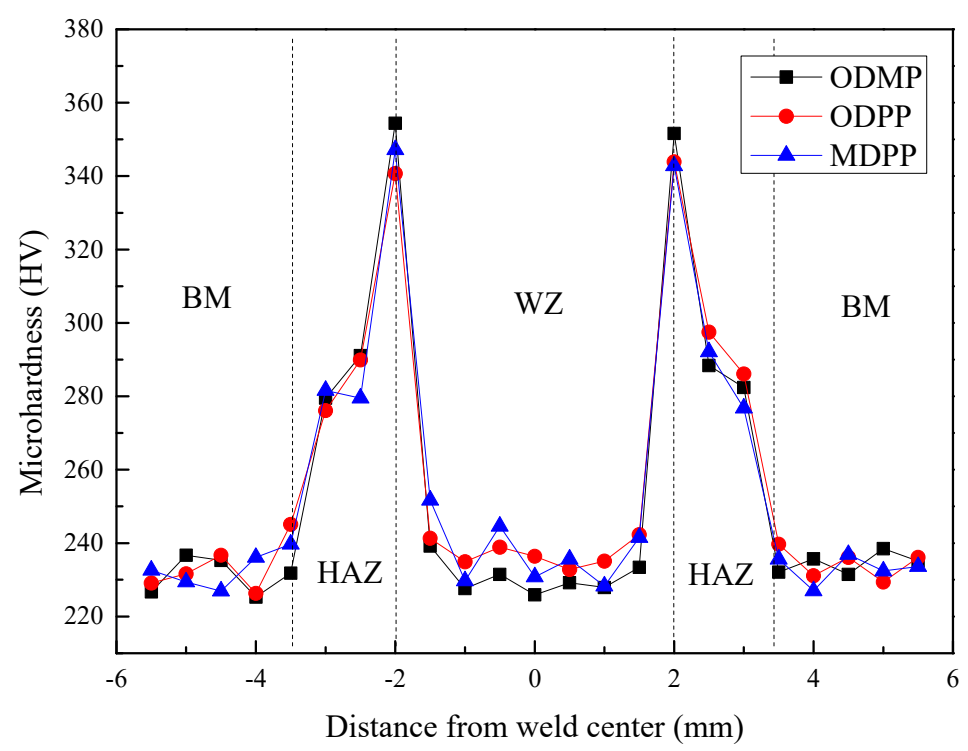

Figure 6. The microhardness of the welded joints with three typical modes of droplet transfer (BM: base metal; HAZ: heat-affected zone; WZ: weld zone).

Figure 7 demonstrates the tensile strengths and elongations of the welded joints with three typical modes of droplet transfer in pulsed GMAW, whose fractures were located in the weld zone near the fusion line. As could be seen in this figure, the ultimate tensile strength of welded joints (three specimens each) with ODMP, ODPP, and MDPP was $580 \mathrm{MPa}, 577 \mathrm{MPa}$, and $566 \mathrm{MPa}$, respectively. The effect of modes of droplet transfer on the tensile strength was little and no more than $3 \%$. However, the modes of droplet transfer had a remarkable influence on the elongation. The elongation of the welded joint in the ODPP condition was the most, which was $7.5 \%$ longer than that in the ODMP condition. The standard deviations of the ultimate tensile strength and the elongation were no more than 20 and 5, respectively. As seen in Table 3, the lower heat input could be obtained in the ODPP condition, while the higher heat input could be gained in the ODMP condition. As mentioned in Section 3.2, the finer and more uniform grains could be grown with the lower heat input and the stronger stirring effect of the molten pool, and vice versa. This is believed to contribute to the higher elongation $[26,30]$.

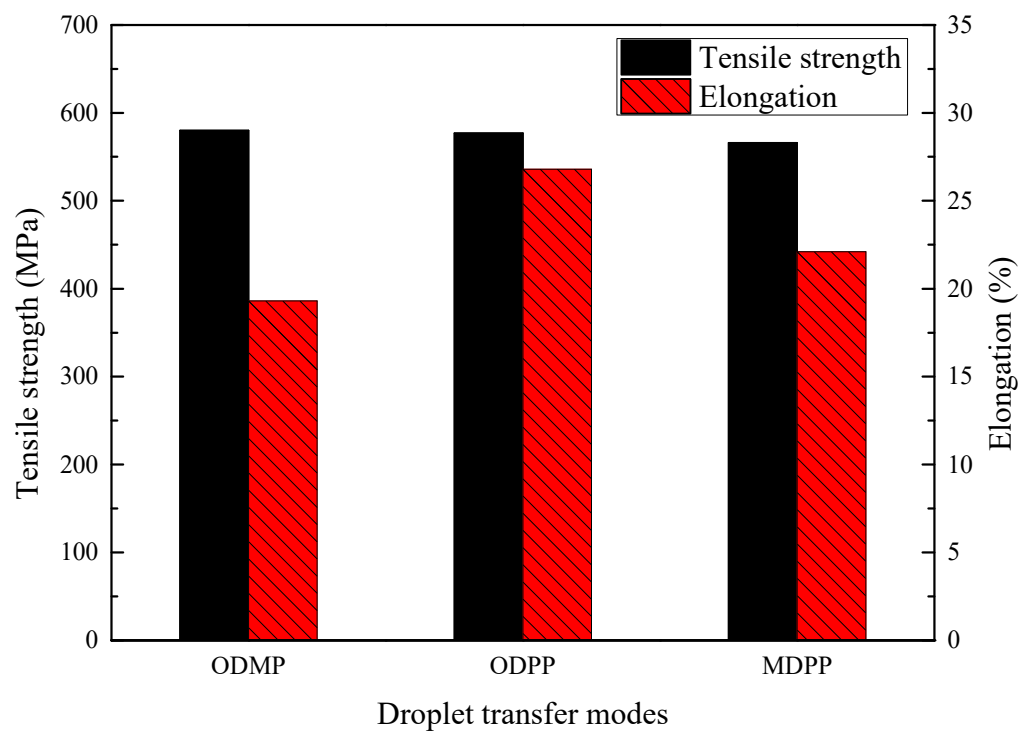

Figure 7. The tensile strengths and elongations of the welded joints with three typical modes of droplet transfer. 


\subsection{Impact Characteristics and Fractography}

The Charpy impact energy of the weld center (three specimens each) in ODMP, ODPP, and MDPP condition was 72,98 , and $84 \mathrm{~J}$, respectively. The variation trend of the impact of energy was similar to the elongations. The highest and lowest impact energy was found in ODPP and ODMP conditions, respectively. The standard deviations in ODMP, ODPP, and MDPP conditions were 5.3, 6.2, and 4.5, respectively. Figure 8 displays the fracture surfaces of impact-tested specimens in the weld zone of three typical modes of droplet transfer. Dimples and microvoids could be found in these three photographs. Comparatively speaking, the dimples were bigger and deeper in Figure $8 b$, which was beneficial for getting greater toughness. This was consistent with the results of Figure 7 . The dimples in Figure 8a,c were smaller and shallower, and the distributions were also non-uniform. Besides, some morphology, like a mixture of quasi-cleavage and dimples, was found in Figure 8a [31]. The results of the Charpy impact test were in agreement with the microstructures. As mentioned in Section 3.2, the PF and the FSP were more and coarser in the ODMP condition, which was harmful to impact toughness since the cleavage cracks propagated easily in these brittle microstructures [32].

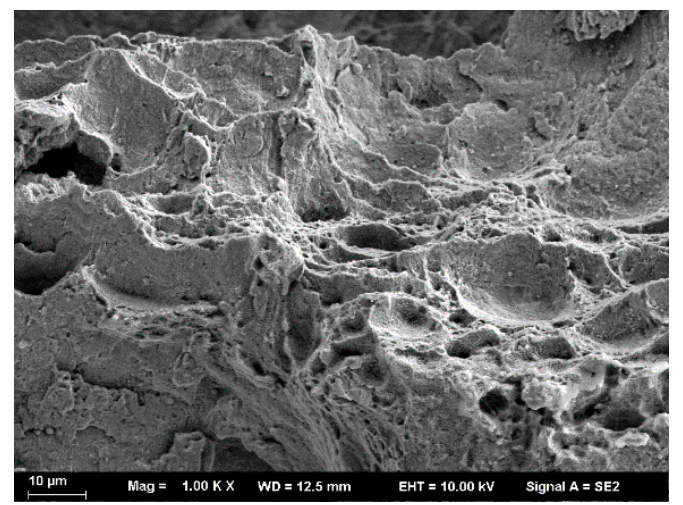

(a)

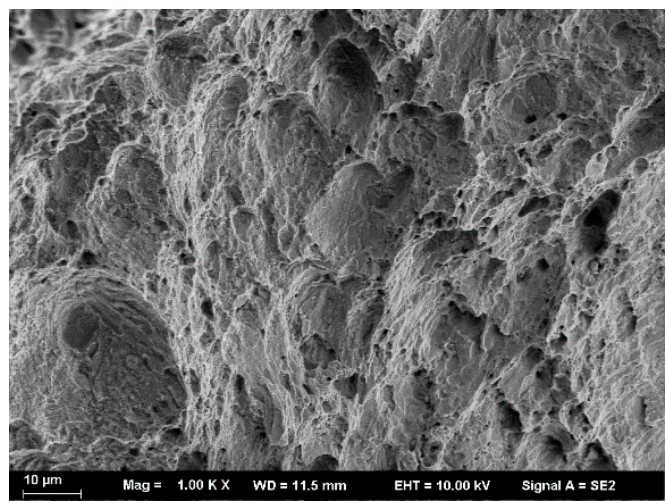

(b)

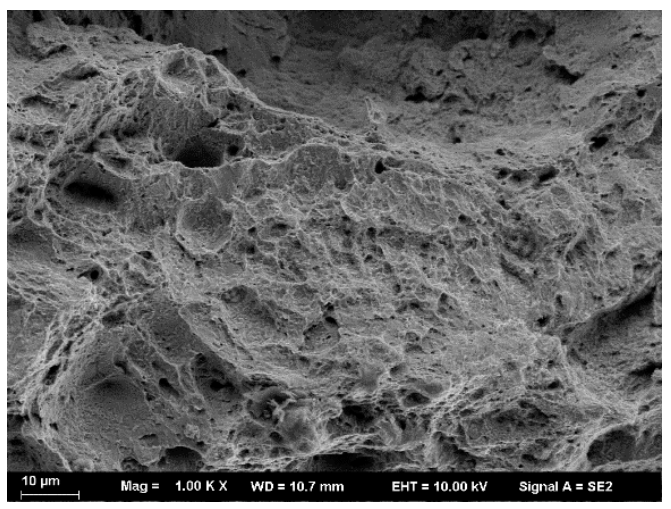

(c)

Figure 8. Fracture surfaces of impact-tested specimens with three typical modes of droplet transfer: (a) one drop per multiple pulses (ODMP); (b) one drop per pulse (ODPP); (c) multiple drops per pulse (MDPP).

\section{Conclusions}

In this work, the appearance, microstructure, microhardness, tensile properties, and impact toughness of Q345 steel welded with three typical modes of droplet transfer (ODMP, ODPP, and MDPP) in pulsed GMAW were studied and compared. The following conclusions could be drawn:

(1) At the same wire feeding speed and arc length, the average current was similar in ODPP and MDPP conditions. However, the average current in the ODMP condition was about 15 A larger 
than the former two, contributing to the higher heat input. Therefore, the proeutectoid ferrite and ferrite side plate were more and coarser in the ODMP condition. Besides, the microstructure of weld metal in the ODPP condition exhibited more uniform distribution compared with MDPP.

(2) Compared with ODMP and MDPP, the smooth, straight, and bright weld bead could be found during the ODPP welding process. A deeper penetration was gained in the ODPP condition, which was about $10 \%$ deeper than that in ODMP and MDPP conditions. Besides, the amount of fume covered on the steel plate after welding in the ODPP condition was less, which could save time in cleaning the surface of the workpiece and improve production efficiency.

(3) The effect of droplet transfer modes on the tensile strength was little. The longest elongation of the welded joint was found in the ODPP condition, which was 7.5\% longer than the shortest one (ODMP condition). The lowest impact energy was found in the weld zone with ODMP droplet transfer. The decease of elongation and impact toughness might result from the coarsen microstructure, like the proeutectoid ferrite and ferrite side plate.

Author Contributions: Methodology, P.Z. and J.W.; investigation, P.Z., W.C., Y.T., T.C., and S.J.; writing一original draft preparation, P.Z.; writing-review and editing, S.X. and P.Z.; supervision, S.X.; project administration, S.X.; funding acquisition, S.X. All authors have read and agreed to the published version of the manuscript.

Funding: This work was funded by the National Natural Science Foundation of China, Grant No. 51675269, and the Priority Academic Program Development of Jiangsu Higher Education Institutions (PAPD).

Conflicts of Interest: The authors declare no conflicts of interest.

\section{References}

1. Chiocca, A.; Frendo, F.; Bertini, L. Evaluation of Heat Sources for the Simulation of the Temperature Distribution in Gas Metal Arc Welded Joints. Metals 2019, 9, 1142. [CrossRef]

2. Cai, X.; Dong, B.; Lin, S.; Murphy, A.B.; Fan, C.; Yang, C. Heat Source Characteristics of Ternary-Gas-Shielded Tandem Narrow-Gap GMAW. Materials 2019, 12, 1397. [CrossRef] [PubMed]

3. Chen, X.; Su, C.; Wang, Y.; Siddiquee, A.N.; Sergey, K.; Jayalakshmi, S.; Singh, R.A. Cold Metal Transfer (CMT) Based Wire and Arc Additive Manufacture (WAAM) System. J. Surf. Ingestig. 2018, 12, 1278-1284. [CrossRef]

4. Yao, P.; Zhou, K.; Lin, H.; Xu, Z.; Yue, S. Exploration of Weld Bead Forming Rule during Double-Pulsed GMAW Process Based on Grey Relational Analysis. Materials 2019, 12, 3662. [CrossRef] [PubMed]

5. Yao, P.; Zhou, K.; Huang, S. Process and Parameter Optimization of the Double-Pulsed GMAW Process. Metals 2019, 9, 1009. [CrossRef]

6. Wang, L.; Xue, J. Perspective on Double Pulsed Gas Metal Arc Welding. Appl. Sci. 2017, 7, 894. [CrossRef]

7. Makles, K.; Winczek, J.; Gucwa, M. Advanced Output Characteristics of Welding Power Source for Pulsed GMAW. In Advances in Manufacturing Engineering and Materials. Lecture Notes in Mechanical Engineering; Hloch, S., Klichová, D., Krolczyk, G., Chattopadhyaya, S., Ruppenthalová, L., Eds.; Springer: Berlin/Heidelberg, Germany, 2019; pp. 307-314.

8. Wang, Q.; Qi, B.; Cong, B.; Yang, M. Output characteristic and arc length control of pulsed gas metal arc welding process. J. Manuf. Process. 2017, 29, 427-437. [CrossRef]

9. Xu, Y.; Lv, N.; Fang, G.; Du, S.; Zhao, W.; Ye, Z.; Chen, S. Welding seam tracking in robotic gas metal arc welding. J. Mater. Process. Technol. 2017, 248, 18-30. [CrossRef]

10. Xu, Y.; Fang, G.; Lv, N.; Chen, S.; Zou, J.J. Computer vision technology for seam tracking in robotic GTAW and GMAW. Robot. Comput.-Integr. Manuf. 2015, 32, 25-36. [CrossRef]

11. Kozakov, R.; Gött, G.; Schöpp, H.; Uhrlandt, D.; Schnick, M.; Häßler, M.; Füssel, U.; Rose, S. Spatial structure of the arc in a pulsed GMAW process. J. Phys. D Appl. Phys. 2013, 46, 224001. [CrossRef]

12. Chen, C.; Fan, C.; Cai, X.; Lin, S.; Yang, C. Analysis of droplet transfer, weld formation and microstructure in Al-Cu alloy bead welding joint with pulsed ultrasonic-GMAW method. J. Mater. Process. Technol. 2019, 271, 144-151. [CrossRef]

13. Dos Santos, E.B.F.; Pistor, R.; Gerlich, A.P. Pulse profile and metal transfer in pulsed gas metal arc welding: Droplet formation, detachment and velocity. Sci. Technol. Weld. Join. 2017, 22, 627-641. [CrossRef] 
14. Hertel, M.; Rose, S.; Füssel, U. Numerical simulation of arc and droplet transfer in pulsed GMAW of mild steel in argon. Weld. World 2016, 60, 1055-1061. [CrossRef]

15. Konovalov, S.; Chen, X.; Sarychev, V.; Nevskii, S.; Gromov, V.; Trtica, M. Mathematical Modeling of the Concentrated Energy Flow Effect on Metallic Materials. Metals 2016, 7, 4. [CrossRef]

16. Xiao, J.; Zhang, G.J.; Zhang, W.J.; Zhang, Y.M. Active Metal Transfer Control by Utilizing Enhanced Droplet Oscillation Part 1: Experimental Study. Weld. J. 2014, 93, 282s-291s.

17. Xiao, J.; Zhang, G.J.; Zhang, W.J.; Zhang, Y.M. Active Metal Transfer Control by Utilizing Enhanced Droplet Oscillation Part II: Modeling and Analysis. Weld. J. 2014, 93, 321s-330s.

18. Pal, K.; Pal, S.K. Effect of Pulse Parameters on Weld Quality in Pulsed Gas Metal Arc Welding: A Review. J. Mater. Eng. Perform. 2011, 20, 918-931. [CrossRef]

19. Ghosh, P.K.; Goyal, V.K.; Dhiman, H.K.; Kumar, M. Thermal and metal transfer behaviours in pulsed current gas metal arc weld deposition of Al-Mg alloy. Sci. Technol. Weld. Join. 2006, 11, 232-242. [CrossRef]

20. Wu, C.S.; Chen, M.A.; Lu, Y.F. Effect of current waveforms on metal transfer in pulsed gas metal arc welding. Meas. Sci. Technol. 2005, 16, 2459-2465. [CrossRef]

21. Rajasekaran, S. Weld Bead Characteristics in Pulsed GMA Welding of AI-Mg Alloys. Weld. J. 1999, 78, 397s-407s.

22. Rajasekaran, S.; Kulkarni, S.D.; Mallya, U.D.; Chaturvedi, R.C. Droplet detachment and plate fusion characteristics in pulsed current gas metal arc welding. Weld. J. 1998, 77, 254s-269s.

23. Zhai, P.; Xue, S.; Chen, T.; Wang, J.; Tao, Y. An Image-Processing Method for Extracting Kinematic Characteristics of Droplets during Pulsed GMAW. Appl. Sci. 2019, 9, 5481. [CrossRef]

24. Ghosh, P.K.; Dorn, L.; Devakumaran, K.; Hofmann, F. Pulsed Current Gas Metal Arc Welding under Different Shielding and Pulse Parameters; Part 1: Arc Characteristics. ISIJ Int. 2009, 49, 251-260. [CrossRef]

25. Ghosh, P.K.; Dorn, L.; Devakumaran, K.; Hofmann, F. Pulsed Current Gas Metal Arc Welding under Different Shielding and Pulse Parameters; Part 2: Behaviour of Metal Transfer. ISIJ Int. 2009, 49, 261-269. [CrossRef]

26. Mirzaei, M.; Arabi Jeshvaghani, R.; Yazdipour, A.; Zangeneh-Madar, K. Study of welding velocity and pulse frequency on microstructure and mechanical properties of pulsed gas metal arc welded high strength low alloy steel. Mater. Des. 2013, 51, 709-713. [CrossRef]

27. Xue, J.; Xu, M.; Huang, W.; Zhang, Z.; Wu, W.; Jin, L. Stability and Heat Input Controllability of Two Different Modulations for Double-Pulse MIG Welding. Appl. Sci. 2019, 9, 127. [CrossRef]

28. Shome, M.; Gupta, O.P.; Mohanty, O.N. Effect of simulated thermal cycles on the microstructure of the heat-affected zone in HSLA-80 and HSLA-100 steel plates. Metall. Mater. Trans. A 2004, 35, 985-996. [CrossRef]

29. Suresh, M.V.; Vamsi Krishna, B.; Venugopal, P.; Prasad Rao, K. Effect of pulse frequency in gas tungsten arc welding of powder metallurgical preforms. Sci. Technol. Weld. Join. 2004, 9, 362-368. [CrossRef]

30. Wei, L.; Nelson, T.W. Influence of heat input on post weld microstructure and mechanical properties of friction stir welded HSLA-65 steel. Mater. Sci. Eng. A 2012, 556, 51-59. [CrossRef]

31. Kurşun, T. Effect of the Gmaw and the Gmaw-P Welding Processes on Microstructure, Hardness, Tensile and Impact Strength of Aisi 1030 Steel Joints Fabricated by ASP316L Austenitic Stainless Steel Filler Metal. Arch. Metall. Mater. 2011, 56, 955-963. [CrossRef]

32. Lippold, J.C. Welding metallurgy and weldability; John Wiley \& Sons, Inc.: Hoboken, NJ, USA, 2015.

(C) 2020 by the authors. Licensee MDPI, Basel, Switzerland. This article is an open access article distributed under the terms and conditions of the Creative Commons Attribution (CC BY) license (http://creativecommons.org/licenses/by/4.0/). 